\title{
BOOK-TAX-DIFFERENCES ANORMAIS E PERSISTÊNCIA DOS RESULTADOS CONTÁBEIS E TRIBUTÁRIOS EM EMPRESAS DE CAPITAL ABERTO LISTADAS NO BRASIL
}

\author{
ABNORMAL BOOK-TAX-DIFFERENCES AND ACCOUNTING AND TAX EARNINGS \\ PERSISTENCE IN PUBLICLY TRADED COMPANIES LISTED IN BRAZIL
}

\section{BOOK-TAX-DIFFERENCES ANORMALES Y PERSISTENCIA DE LOS RESULTADOS FINANCEIROS Y EL IMPUESTO SOBRE SOCIEDADES PÚBLICAS COTIZADAS EN BRASIL}

Recebido em: 15/02/2017

Avaliado em: 11/09/2018

Reformulado em:19/09/2018

Aceito para publicação em: 29/11/2018

Publicado em: 14/06/2019

Editor Responsável: Moacir M. Rodrigues Junior
Antônio Carlos Brunozi Júnior ${ }^{1}$

Clóvis Antônio Kronbauer²

Tiago Wickstrom Alves ${ }^{3}$

Antônio Lopo Martinez ${ }^{4}$

\section{RESUMO}

Este estudo teve como objetivo avaliar as relações das $B T D$, como reflexos de atividades para o gerenciamento de resultados, na persistência dos resultados contábeis e tributários em empresas de capital aberto listadas no Brasil. É uma pesquisa que contribui no país ao relacionar as BTD Anormais com a qualidade dos lucros em períodos anteriores e posteriores às IFRS. Para atingir a essas pretensões, este estudo considerou 290 empresas não financeiras listadas na B3, no período de 2002 a 2015. Foi aplicada a técnica de dados em painel dinâmico com o método de momentos generalizados $(G M M)$. Os resultados revelaram que as BTD Anormais e a sua interação com os accruals diminuem a persistência dos resultados contábeis na amostra. Para a persistência dos resultados tributários, as BTD Anormais individualmente, e suas interações com os accruals e o fluxo de caixa operacional influenciaram negativamente a previsão dos resultados tributários futuros. Com isso, neste estudo, há implicações sobre que as BTD devem ser consideradas pelos seus componentes, com os discricionários causando assimetria informacional e afetando a qualidade dos lucros nas empresas. Além disso, observou-se que, com as IFRS, a separação Book-Tax pode ser desfavorável, principalmente devido à subjetividade da Contabilidade Financeira, não causando os efeitos de melhorias informacionais desejados com a criação destes padrões.

Palavras-chave: Book-Tax Differences; Book-Tax Differences Anormais; Qualidade dos Resultados Contábeis e Tributários; Persistência; Brasil.

\footnotetext{
${ }^{1}$ Doutor em Ciências Contábeis pela Universidade do Vale do Rio dos Sinos (UNISINOS); Professor do Departamento de Administração e Contabilidade da Universidade Federal de Viçosa; E-mail: acbrunozi@yahoo.com.br

${ }^{2}$ Doutor em Contabilidad y Auditoria - Universidade de Sevilla - Espanha; Professor do Programa de Pós-Graduação em Ciências Contábeis da Universidade do Vale do Rio dos Sinos (UNISINOS); E-mail:clovisk@ unisinos.br

${ }^{3}$ Doutor em Economia pela Universidade Federal do Rio Grande do Sul; Professor dos Programas de Pós-Graduação em Ciências Contábeis e Economia da Universidade do Vale do Rio dos Sinos (UNISINOS); E-mail: twass@unisinos.br

${ }^{4}$ Doutor em Controladoria e Contabilidade pela Universidade de São Paulo (USP); Professor-associado da Fucape Business School; E-mail: lopo@ fucape.br
} 


\begin{abstract}
The study aimed to evaluate the relationships of BTD, as a reflection of activities for the earnings management, in the accounting and tax earnings persistence in listed companies listed in Brazil. It is a research that contributes in the country when relating the Abnormal BTD with the earnings quality in periods before and after the IFRS. To achieve this, this study considered 290 non-financial companies listed in B3, from 2002 to 2015 . The dynamic panel data technique was applied using the generalized moments (GMM) method. The results revealed that the abnormal BTD and their interaction with the accruals decrease the accounting earnings persistence in the sample. For the tax earnings persistence, the individual abnormal BTD, and their interactions with the accruals and the operating cash flow, had a negative influence on the forecast of the future tax results. Thus, in this study, there are implications on which BTD should be considered by its components, with the discretionary ones causing informational asymmetry and affecting the earnings quality in companies. In addition, it was observed that with IFRS, Book-Tax separation can be unfavorable, mainly due to the subjectivity of Financial Accounting, not causing the effects of desired informational improvements with the creation of these standards.
\end{abstract}

Keywords: Book-Tax Differences; Abnormal Book-Tax Differences; Accounting and Tax Earnings Quality; Earnings Persistence; Brazil.

\title{
RESUMEN
}

Este estudio tuvo como objetivo evaluar las relaciones de las BTD, como reflejos de actividades para la manipulación de resultados, en la persistencia de los resultados contables y tributarios en empresas de capital abierto listadas en Brasil. Es una investigación que contribuye en el país al relacionar las BTD Anormales con la calidad de los resultados en períodos anteriores y posteriores a las NIIF. Para alcanzar estas pretensiones, este estudio consideró 290 empresas no financieras listadas en la B3, en el período de 2002 a 2015. Se aplicó la técnica de datos en panel dinámico con el método de momentos generalizados (GMM). Los resultados revelaron que las BTD anormales y su interacción con los accruals disminuyen la persistencia de los resultados contables en la muestra. Para la persistencia de los resultados tributarios, las BTD Anormales individualmente, y sus interacciones con los accruals y el flujo de caja operacional influenciaron negativamente la previsión de los resultados tributarios futuros. Con ello, en este estudio, hay implicaciones sobre que las BTD deben ser consideradas por sus componentes, con los discrecional causando asimetría informacional y afectando la calidad de los resultados en las empresas. Además, se observó que, con las NIIF, la separación Book-Tax puede ser desfavorable, principalmente debido a la subjetividad de la Contabilidad Financiera, no causando los efectos de mejoras informacionales deseados con la creación de estos estándares.

Palabras-clave: Book-Tax Differences; Anormales Book-Tax Differences; Calidad de los resultados financieros e fiscales; La Persistencia; Brasil.

\section{INTRODUÇÃO}

Na literatura contábil, nacional e internacional, tem-se apresentado nos últimos anos que as Book-Tax Differences (BTD) relacionam-se com a qualidade dos resultados contábeis (Earnings Quality) em empresas de diversos países. As pesquisas, por exemplo, de Hanlon e Heitzman (2010); Hanlon (2005), e Lev e Nissim (2004), indicaram que as BTD possuem papeis informativos e podem afetar a previsibilidade, a variabilidade, a relevância e o reconhecimento tempestivo dos dados contábeis. No entanto, estes estudos e outros nacionais (Cardoso, Costa \& Ávila, 2016; Moraes; Sauerbronn \& Macedo, 2015; Nakao, 2012; Costa, 2012) não esclareceram ou evidenciaram suficientemente as informações contidas nos diferentes componentes das BTD. Em geral, estas pesquisas assumiram que as $B T D$ são decorrentes, somente, de diferenças nos arranjos normativos 
das apurações contábeis e fiscais (Lucro Contábil - Lucro Tributário). Porém, essas diferenças Book-Tax não têm só origens nas normas da Contabilidade e nas regras fiscais, mas também são reflexos de ações para gerenciar os resultados contábeis e/ou os lucros fiscais (Pereira, 2010).

Tang e Firth (2011) e Tang (2006) foram os primeiros pesquisadores a perceber que as BTD são formadas por diferentes componentes informacionais, sendo que eles os denominaram de $B T D$ Normais e BTD Anormais. Segundo Noga e Schnader (2013) e Tang e Firth (2011), esses tipos de $B T D$ podem ser explicadas por suas legitimidades e razões questionáveis. As BTD Normais representam as diferenças inerentes e legítimas da Contabilidade Financeira e da Contabilidade Tributária, ou seja, as diferenças permanentes e temporárias. Enquanto as BTD Anormais incluem motivações questionáveis dos gestores para as manipulações dos resultados e normas contábeis, as evasões fiscais ou a utilização ilegal de benefícios tributários. Em resumo, as BTD podem ser compostas por fatores regulatórios e discricionários nas empresas (Tang \& Firth, 2011).

Formigoni et al. (2012) reforçam o entendimento das BTD por seus diferentes componentes. Para os autores, há evidências de que as empresas utilizam a subjetividade permitida pela Contabilidade para a diminuição da carga tributária. Os gestores utilizam os accruals das escolhas contábeis, por exemplo, para influenciar a percepção do mercado e os retornos das ações (Field, Lys \& Vicent, 2001); alisar os resultados contábeis (Carvalho, 2015); preservar o cargo e a busca por maiores remunerações (Healy \& Wahlen, 1999) e motivos contratuais de dívidas ou obtenção de novos empréstimos (Field, Lys \& Vicent, 2001), mas também para reduzir o lucro tributável e, consequentemente, recolher menos impostos. Esse cenário evidencia a tendência de que as BTD Anormais são possíveis reflexos da manipulação conjunta dos lucros contábeis e dos fiscais.

Assim, percebe-se que existem fundamentos necessários para demonstrar que essa separação dos componentes das BTD trouxe uma maior sustentação para justificar as relações das BTD na qualidade dos resultados contábeis, principalmente as BTD Anormais, foco a ser discutido. Para Tang e Firth (2012) e Hanlon (2005), detectar as BTD como consequências de ações para os gerenciamentos de resultados e tributos é um importante indicativo para a qualidade dos lucros, pois essas práticas de manipulação conduzem a assimetria informacional nas empresas.

No Brasil, as BTD Anormais podem ser fundamentadas em seu cenário institucional. Segundo Machado e Nakao (2012), até o ano de 2007/2008 a prática contábil brasileira sofria forte influência da legislação tributária, mas com a promulgação das International Financial Reporting Standards IFRS houve a separação formal entre a Contabilidade para fins fiscais e a Contabilidade para divulgação externa. Assim, houve no país a legitimação da convergência internacional contábil, permitindo as aplicações das normas contábeis e fiscais sob distintos incentivos, objetivos e usuários (Costa, 2012). As principais metas nesse processo de adoção foram as melhorias da qualidade dos resultados reportados para os investidores e credores no Brasil.

No entanto, apesar desse desalinhamento contábil-fiscal com as IFRS, é questionável no Brasil se as $B T D$ são utilizadas como dispositivos de desenvolvimentos informacionais para a qualidade dos lucros nas empresas. Os questionamentos são se as BTD mantiveram ou modificaram suas relações com a qualidade dos lucros das empresas nos períodos anteriores e posteriores à implementação das IFRS. Essa indagação é válida, pois os dados dos estudos de Cardoso, Costa e Ávila (2016), e Moraes, Sauerbronn e Macedo (2015) mostraram que ocorreram variações das BTD durante os anos. As dúvidas sobre esse tema ainda são confirmadas na própria literatura nacional (Furtado, Souza \& Sarlo Neto, 2016; Martinez \& Basseti, 2016; Martinez, Souza \& Monte-Mor, 2016; Costa, 2012; Nakao, 2012).

Diante disso, considerando que as BTD Anormais são indícios de assimetria informacional, que justificam a sua relação com a qualidade dos resultados contábeis, esse estudo tem como objetivo geral avaliar as relações das $B T D$, como reflexos de atividades para o gerenciamento de resultados, na persistência dos resultados contábeis e tributários em empresas de capital aberto listadas no Brasil.

A persistência dos resultados é uma característica desejada para os dados contábeis, pois pode indicar tendências da saúde financeira em períodos presentes e futuros das empresas, determinar o 
valor da firma e ainda tem relevância para os investidores (Dechow, Ge \& Schrand, 2010). Além disso, conforme Hanlon (2005), as BTD, como são reflexos de ações para gerenciar os resultados, têm potencial para afetar a persistência por meio da subjetividade dos accruals contidos na Contabilidade principalmente. Com isso, os investidores podem sub ou superestimar os correntes e futuros resultados das empresas.

O presente estudo possui contribuições teóricas. Primeiramente, nesta pesquisa há a proposição de modelagem inovadora para apurar as BTD Normais e Anormais em um contexto brasileiro, complementando outros estudos internacionais (Dridi \& Adel, 2016; Tang \& Firth, 2012; Bouaziz \& Omri, 2011; Tang \& Firth, 2011; Tang, 2006). Estes estudos anteriores replicaram Tang e Firth (2011) sem uma aplicação delimitada aos contextos dos países analisados. Nesta pesquisa, seguiu-se para as BTD Anormais as recomendações de Carvalho (2015), de considerar aspectos locais na estimação delas, como: a equivalência patrimonial, juros sobre o capital próprio, operações de câmbio e transações internacionais, diferentemente dos modelos aplicados pelos autores de outros países com Tang e Firth (2011); segundo, na literatura nacional este estudo é diferente ao relacionar as BTD Anormais com a qualidade dos lucros. As pesquisas anteriores demonstraram implicações com os honorários de auditoria, níveis de governança diferenciados e estrutura de capital (Marques, Nakao \& Costa, 2017; Ávila, 2016; Onezorge \& Teixeira, 2016); terceiro, sobre as BTD Anormais proposta, esta pesquisa se diferencia de Carvalho (2015); Martinez e Passamani (2014); Piqueiras (2010), e Formigoni et al. (2009) que utilizaram essa variável com o modelo de Tang e Firth (2011), sem adaptações ao contexto nacional e ainda com a consideração de fatores explicativos das características das empresas. Além disso, esta investigação se diferencia de Furtado, Souza e Sarlo Neto (2016); Martinez, Souza e Monte-Mor (2016); Martinez e Basseti (2016), e Martinez e Dalfior (2015), que somente utilizaram as BTD sem a separação de componentes, ou seja, Lucro antes dos impostos sobre o lucro (LAIR) subtraído do Lucro tributário estimado; quarto, esta pesquisa apresenta resultados para períodos anteriores e posteriores à adoção das IFRS, e quinto, este trabalho demonstrou resultados quanto à efetividade temporal das normativas.

As contribuições empíricas são de que o modelo proposto para as BTD Anormais é explicativo e contempla variáveis que são inerentes ao contexto contábil-fiscal brasileiro. Notou-se que esta proxy possui associações positivas com as variáveis de gerenciamento de resultados e negativas com métricas de compliance tributária. Por meio dos resultados, percebeu-se que as BTD Anormais diminuem as persistências dos resultados tributários principalmente, no período de 2002 a 2015. Estas afetações foram mais intensas após a adoção das IFRS para ambas as persistências. Para a persistência dos resultados contábeis, as BTD Anormais têm mais implicações quando são consideradas em conjunto com os accruals.

\section{REFERENCIAL TEÓRICO}

\subsection{As Book-Tax Differences e a Qualidade dos Resultados Contábeis}

As $B T D$, que foram pesquisadas inicialmente nos Estados Unidos e na Europa nas décadas de 1990/2000 devido às mudanças nas apurações da Contabilidade e dos tributos nos países, representam as diferenças entre os resultados apurados para fins contábeis e fiscais (Hanlon, 2005). Elas estão relacionadas aos conceitos de conformidade contábil-fiscal e possuem pesquisadores favoráveis (Blaylock, Gaertner \& Shevlin, 2015; Hanlon, Mayden \& Shevlin, 2008) e desfavoráveis (Tang, 2015; Lev \& Nissim, 2004) quanto às suas magnitudes.

As BTD são reconhecidas como importantes para as necessidades informacionais (Chi, Pincus $\&$ Teoh, 2014). Elas surgem de uma variedade de fatores, sendo os principais: as diferenças permanentes e temporárias, e os componentes Normais (normativos) e Anormais (discricionários).

As diferenças permanentes e temporárias surgem das heterogeneidades existentes entre as normativas contábeis e as legislações fiscais, ou seja, as operações de uma empresa são tratadas de uma maneira na Contabilidade Financeira e de outra na Contabilidade Tributária. As diferenças 
temporárias diferem as normas contábeis e fiscais somente no período em que alguns elementos financeiros e patrimoniais são reconhecidos nas empresas (Comprix, Graham \& Moore, 2011). Enquanto as diferenças permanentes não são uma questão de tempestividade, mas de diferentes tratamentos para as despesas e receitas nas empresas, surgindo as figuras de valores não dedutíveis ou tributáveis nas duas Contabilidades (Frank, Lynch \& Rego, 2009).

Independentemente dessas duas medidas (temporária e permanente), deve-se entender as BTD como um todo (Comprix, Graham \& Moore, 2011), ou seja, considerando-se não somente a magnitude dos mecanismos de discrepâncias entre as regras Book e Tax, mas também elas como reflexos de atividades para gerenciar os dados contábeis e/ou os tributos (Tang \& Firth, 2011). Assim, considera-se nessa relação de desalinhamento entre as diferenças Book-Tax, as BTD Normais (Não Discricionárias) e as BTD Anormais (Discricionárias) (Tang \& Firth, 2011; Tang, 2006).

Brown et al. (2014) e Tang (2006) as compõe em duas perspectivas. A primeira pode surgir dos diferentes mecanismos das normas contábeis e fiscais (diferenças não discricionárias) e a segunda (diferenças discricionárias) são consequências dos julgamentos dos gestores por meio do gerenciamento de resultados e o planejamento agressivo fiscal.

Com base no exposto, é importante esclarecer que na literatura desenvolveu-se a consideração das $B T D$ sob essas diferentes origens supracitadas, e com isso as pesquisas as relacionaram com diversos outros assuntos, como: Ciclos de vida nas empresas, Compliance tributária, Custo de capital, estrutura de capital, honorários de auditoria, qualidade dos lucros e rantings de créditos. No entanto, para o presente estudo discute-se as relações das BTD com a qualidade dos lucros.

Para esta pesquisa, o conceito de qualidade dos lucros é relacionado à utilidade das informações das empresas, capturando e reportando os modelos de negócios e o ambiente operacional das entidades (Dechow, Ge \& Schrand, 2010). As informações contábeis são qualitativas quando são preditoras, conservadoras, não gerenciadas, tempestivas e relevantes.

Neste estudo foi considerada a relação das BTD com as persistências dos resultados contábeis e tributários, sendo que outras pesquisas sustentam essa associação. Na literatura sobre esse tema há diversos trabalhos que consideraram as $B T D$ sem a separação de componentes Normais e Anormais e com relações positivas e negativas sobre a persistência dos resultados em empresas do Brasil, China, Estados Unidos, Europa, Indonésia, Japão e nações africanas e dos Emirados Árabes Unidos (Martinez \& Basseti, 2016; Martinez, Souza \& Monte-Mor, 2016; Jackson, 2015; Blaylock, Shevlin \& Wilson, 2012; Martani, Fitriasari \& Yulianti, 2010; Yamashita et al., 2007; Hanlon, 2005; Lev \& Nissim, 2004). Em relação às implicações das BTD Anormais, foco deste estudo, poucos são as investigações que analisaram os efeitos negativos sobre a persistência dos resultados, sendo somente os autores: Dridi e Adel (2016); Bouaziz e Omri (2011), e Tang e Firth (2011).

\subsection{Hipóteses do Estudo}

\subsubsection{As BTD Anormais e a Persistência dos Resultados Contábeis e Tributários}

Para o presente estudo é importante discorrer que as BTD podem ser discutidas sob a ótica da assimetria informacional. Com isso, para as construções das hipóteses teóricas seguiu-se a tendência na literatura de que existem incentivos dos gestores para a manipulação dos resultados por meio das normas contábeis e fiscais, que afetam as informações reportadas pela Contabilidade. Segundo Tang e Firth (2011), quando os gestores têm motivos para distorcer a performance e os resultados das firmas, eles podem oportunisticamente utilizar os padrões contábeis e as normas tributárias para a criação das BTD Anormais.

Essas práticas discricionárias das $B T D$ apontam que as firmas podem se engajar tanto em reportes agressivos contabilmente, como em ações oportunas para as evidenciações tributárias (Desai \& Dharmapala, 2009; Dhaliwal, Lee \& Pincus, 2009). Frank, Lynch e Rego (2009) e Hanlon (2005) apontaram três direcionamentos que evidenciam o engajamento e os incentivos dos gestores para essas manipulações contábeis e as tributárias, sendo: i) os gestores podem gerenciar os Lucros Contábil e o Tributário em direções opostas, como por exemplo, aumentando os Lucros Contábeis 
reportados e diminuindo os resultados fiscais ou vice-versa; ii) os gestores podem manter os Lucros Tributários constantes e manipular os resultados contábeis para caminhos de recorrentes ganhos, e iii) nas empresas pode ocorrer a opção dos gestores por manterem os Lucros Contábeis constantes, com a indicação de práticas para a redução ou alisamento dos impostos. Apesar destas três escolhas dos gestores, é possível afirmar que as finalidades são congruentes, ou seja, as práticas de gerenciamentos de resultados e/ou tributos influenciando os resultados contábeis e os pagamentos de impostos. Como consequência, essas ações aumentam as variações das $B T D$, refletindo-se na discricionariedade desses componentes Book-Tax (Tang, 2006).

Esses indicativos apresentados só reforçam as BTD Anormais, como reflexos de práticas de manipulação de resultados contábeis e/ou tributários, conduzindo aos entendimentos de que esses tipos de gerenciamentos estão relacionados significativamente com a queda da qualidade dos resultados contábeis (Hanlon, 2005).

Dhaliwal, Lee e Pincus (2009) argumentaram que as BTD, como fontes de variabilidades discricionárias dos padrões contábeis e das normas fiscais, podem ser origens de incertezas sobre a qualidade dos lucros. Essas variações das BTD podem refletir incertezas sobre as atividades e as performances das firmas.

Hanlon (2005) salientou essa relação contrária entre as BTD e a qualidade dos resultados contábeis. Ela reforçou que, quando utilizadas para manipular os resultados, são indícios para a redução da qualidade dos lucros reportados nas empresas, uma "red flag". Dridi e Adel (2016) e Jackson (2015) confirmaram que as BTD são consequências decorrentes da manipulação dos resultados e podem limitar a efetividade da Contabilidade em transmitir informações consistentes e úteis aos seus usuários.

Quando se limita as relações entre as BTD Anormais e a persistência dos resultados, é possível perceber as mesmas constatações apresentadas anteriormente. Dridi e Adel (2016), e Bouaziz e Omri (2011), mesmo com diferentes modelagens para as BTD Anormais, verificaram que na Tunísia esses componentes das $B T D$ diminuíram a persistência dos resultados contábeis devido à alta tendência dos gestores em gerenciarem os resultados contabilmente e fiscalmente. Já Tang e Firth (2011), em um contexto chinês, observaram que de 1999 a 2004 as BTD Anormais relacionaram-se negativamente com a persistência dos resultados contábeis. Na China, devido à pressão por elevados retornos, é recorrente o comportamento discricionário dos gestores para apresentarem lucros altos e baixos impostos.

Com essa exposição, a hipótese $1_{\mathrm{a}}$ deste estudo é a seguinte:

$H_{1 a}$ : As BTD Anormais, decorrentes das manipulações dos resultados contábeis e tributários, diminuem a persistência dos resultados contábeis em empresas de capital aberto listadas no Brasil.

Lev e Nissim (2004) apontaram que os lucros tributários também são informativos para os resultados e as performances das empresas. No entanto, os autores discorreram que valores mais altos das BTD podem afetar a capacidade preditiva desses resultados. Com isso, buscando evidenciar percepções adicionais, nesta pesquisa formulou-se a seguinte hipótese:

$H_{1 b}$ : As BTD Anormais, decorrentes das manipulações dos resultados contábeis e tributários, diminuem a persistência dos resultados tributários em empresas de capital aberto listadas no Brasil.

As formulações das hipóteses desta pesquisa no Brasil são confirmadas pelas características peculiares desse país em relação às práticas contábeis e tributárias. Primeiro, essa nação possui um sistema fiscal altamente complexo e com várias incidências tributárias sobre o consumo, patrimônio, produção e lucros (Carvalho, 2015). Segundo, o Brasil, recentemente, passou por uma significativa mudança em seus padrões contábeis com as IFRS, podendo afetar sua estrutura code-law e o desenvolvimento do mercado de capitais (Nakao, 2012). Terceiro, nas outras pesquisas identificaram- 
se uma tendência para o aumento das BTD (Moraes Sauerbronn \& Macedo, 2015) com consistência e persistência ao longo dos anos (Cardoso, Costa \& Ávila, 2016). Quarto, os estudos anteriores são mistos em apontar se as empresas brasileiras possuem satisfatórias qualidades dos resultados contábeis em suas diversas características (Santos \& Cavalcanti, 2014).

Este estudo também adicionou observações sobre as relações das BTD Anormais, a persistência dos resultados e as IFRS. Há na literatura um entendimento, por um lado, de que as IFRS melhoraram a qualidade das informações contábil-financeiras divulgadas pelas organizações. Por outro lado, também há discussões de que as IFRS não foram implementadas adequadamente e efetivamente nos países, permitindo representativa discricionariedade aos gestores nas escolhas das práticas contábeis e prejudicando a informação contábil-financeira reportada (Jeanjean \& Stolowy, 2008).

É com base no segundo argumento, devido ao cenário brasileiro, que este estudo constrói as hipóteses. Para Lyu et al. (2014), devido a característica da essência sobre a forma, as IFRS envolvem consideráveis julgamentos e a utilização de informações privadas pelas empresas. Além disso, os padrões contábeis são permissivos para as escolhas quanto aos tratamentos e incentivos de evidenciação (Ahmed, Chalmers \& Khlif, 2013). Como consequência, os resultados das firmas provêm substancial discricionariedade, o que limita os efeitos positivos das IFRS. Além disso, é recorrente nas pesquisas de outros autores que as IFRS não foram aplicadas adequadamente nos países, pois as estruturas insatisfatórias das empresas, o despreparo dos profissionais, os incentivos para a manipulação dos resultados, o mercado de capitais pouco desenvolvido e os custos limitam uma abrangência mais ampla dessas normativas (Lyu et al., 2014; Bradshaw \& Miller, 2008).

Nesse contexto, os indícios para que as BTD, mesmo nas IFRS, possam ser utilizadas discricionariamente pelos gestores, geram tendências para as BTD Anormais. No Brasil, esta relação pode ser argumentada com a quebra da conformidade financeira-fiscal após as IFRS, de 2008 a 2015. Adicionalmente a isso, o país possui problemas para a adaptação completa às IFRS (Santos \& Cavalcante, 2014), o que pode induzir aos gestores das empresas em utilizarem as BTD como reflexos para a manipulação dos resultados contábeis. Ainda é possível de se relatar que as BTD Anormais podem ser decorrentes dos contínuos incentivos para a evasão fiscal.

Com base nisso, considerou-se que após as IFRS no Brasil, o possível aumento das $B T D$, a presença dos recorrentes julgamentos dos gestores e os incentivos para o planejamento tributário agressivo tornaram as implicações das BTD Anormais na qualidade dos resultados contábeis mais pronunciados. Com isso, as hipóteses 2 são apresentadas a seguir:

$H_{2 a}$ : A diminuição da persistência dos resultados contábeis em empresas de capital aberto listadas no Brasil devido às BTD Anormais é maior após a adoção das IFRS;

$H_{2 b}$ : A diminuição da persistência dos resultados tributários em empresas de capital aberto listadas no Brasil devido às BTD Anormais é maior após a adoção das IFRS.

\section{PROCEDIMENTOS METODOLÓGICOS}

\subsection{População, Amostra e Dados Coletados}

Para este estudo, considerou-se como população os 615 títulos de ações, sejam ordinários, preferenciais e outras modalidades, que representam as empresas listadas no Brasil no período de 2002 a 2015. As informações dessas empresas foram coletadas na base de dados da Economática® para as variáveis contábeis, financeiras, técnicas, tributárias e de mercado, constantes nos relatórios contábil-financeiros e técnicos. Porém, para a consistência e validação dos dados aplicados nessa pesquisa, as bases de dados ORBIS® e COMPUSTAT® também foram utilizadas. Além disso, manualmente, levantou-se dados disponibilizados no sítio daB3 e nas notas explicativas das empresas 
analisadas. As informações sobre os lucros estrangeiros das firmas da amostra foram coletadas no sítio do Ministério de Desenvolvimento, Indústria e Comércio Exterior.

Sobre as diferentes bases de dados utilizadas, a maioria dos dados foi coletada na Economática®. No entanto, dados de equivalência patrimonial e variação cambial foram obtidos nas bases ORBIS® e COMPUSTAT®. Para se evitar as divergências nos agrupamentos dos dados, foram verificadas as definições de cada variável nas bases e ainda houve a conciliação das informações com os reportes das empresas na B3.

Para a composição da amostra final, alguns procedimentos foram realizados, sendo: i) foram retiradas as empresas que não possuíam dados necessários para a operacionalização e ainda foi considerado somente um único tipo de ação - com preferência para as ações mais líquidas - para cada empresa, o que totalizou na exclusão de 220 unidades de análises; ii) foram retirados os títulos acionários que representavam as empresas dos setores financeiros, instituições financeiras, seguradoras, fundos e holdings, perfazendo a exclusão de 97 títulos, e iii) considerou-se a presença de outliers na amostra. Com o auxílio do software livre GeoDa ${ }^{\mathrm{TM}}$, apurou-se oito firmas discrepantes, sem repetição de tipos acionários, que foram retiradas da amostra. Os testes de estatísticas descritivas, correlações, Boxplot e Biplots do Eviews ${ }^{\circledR}$ confirmaram esses dados com variações extremas. Os outliers eram bem divergentes para a amostra, apresentando valores muito pequenos ou significativamente elevados. Logo, a amostra final do estudo compôs-se de 290 empresas e 4.060 observações (que variam nos testes), com um único tipo de ação para cada empresa.

\subsection{Estimando as BTD Anormais}

O presente estudo partiu dos estudos de Tang e Firth (2011) e Tang (2006) para a construção do modelo das BTD Anormais no contexto brasileiro. Para tanto, é importante delinear os passos para a sua estimação. Na perspectiva de operacionalizar as BTD Anormais, esta pesquisa dividiu as $B T D$ em dois componentes: o primeiro representa uma reunião de variáveis que explica as diferenças entre as normas contábeis e as fiscais, ou seja, as diferenças permanentes e temporárias. Essas variáveis indicam que as operações das empresas são tratadas de uma maneira na Contabilidade Financeira e de outra na Contabilidade Tributária. Além disso, essas variáveis são identificadas como dimensões que são menos prováveis de serem práticas para a manipulação dos resultados contábeis e tributários e comporão a parcela das $B T D$ denominada de $B T D$ Normais. O segundo componente das $B T D$ representa os resíduos ou a parcela que não é explicada por esse conjunto das variáveis normais do primeiro componente das $B T D$, isto é, a diferença remanescente das $B T D$ que são reflexos de atividades para a manipulação dos resultados contábeis e tributários, as BTD Anormais.

Com base nisso, a partir da literatura e das normativas contábeis e fiscais, como as Leis 6.404/1976, 11.638/2007, 11.941/2009, 12.973/2014 e os Regulamentos do Imposto de Renda e Contribuição Social sobre o Lucro Líquido, a presente pesquisa apurou que nove variáveis poderiam ser passíveis de explicar as BTD Normais em empresas de capital aberto listadas no Brasil. Com isso, definiu-se o modelo para esse estudo.

Essas variáveis - estoques, imobilizado, intangíveis/diferidos, juros sobre o capital próprio, lucros estrangeiros, prejuízos fiscais, resultados de equivalência patrimonial, variação cambial e variação das receitas de vendas - representam as operações das empresas que podem gerar as $B T D$ e são menos prováveis de serem manipuladas pelos gestores para a variação dos resultados contábeis ou o planejamento tributário agressivo. A parcela não explicada por esses fatores seria as BTD Anormais, interesse desta pesquisa. A equação (1) apresenta o modelo:

$$
\begin{gathered}
B T D_{i, t}=\beta_{1} E Q P_{i, t}+\beta_{2} E S T_{i, t}+\beta_{3} I M O B_{i, t}+\beta_{4} I N T G_{i, t}+\beta_{5} J C P_{i, t}+\beta_{6} L E S G_{i, t}+\beta_{7} P F_{i, t} \\
+\beta_{8} V R V_{i, t}+\beta_{9} V C A M B_{i, t}+\alpha_{i}+\varepsilon_{i, t}
\end{gathered}
$$


Em que, $\mathrm{i}$ - empresas, $\mathrm{t}$ - anos, $\alpha_{i}$ : são interceptos específicos para cada unidade que afetam a relação da variável dependente e as demais, e $\varepsilon_{i, t}$ : erro residual da regressão - BTD Anormais. Dividiu-se as variáveis pelo ativo total em t. As descrições das variáveis estão no Quadro 1.

Quadro 1 - Variáveis e fundamentações para as apurações das BTD Normais e Anormais

\begin{tabular}{|c|c|c|c|c|}
\hline \multirow{2}{*}{ Variáveis } & \multirow{2}{*}{ Siglas } & \multirow{2}{*}{ Mensuração } & \multicolumn{2}{|c|}{ Fundamentações } \\
\hline & & & Contábil & Fiscal** \\
\hline $\begin{array}{l}\text { Equivalência } \\
\text { Patrimonial }\end{array}$ & EQP & Valores da DRE & 6.404/76*/CPC 18 (IAS 28) & Art. 389, RIR/1999 \\
\hline Estoques & EST & Valores do BP & 6.404/76*/CPC 16 (IAS 2) & Art. 296, RIR/1999 \\
\hline Imobilizado & IMOB & Valores do BP & $6.404 / 76 * /$ CPC 27 (IAS 16) & Art. $313, \mathrm{RIR} / 1999$ \\
\hline Intangíveis/diferidos & INTG & Valores do BP & $6.404 / 76 * /$ CPC 04 (IAS 38) & Art. $313, \mathrm{RIR} / 1999$ \\
\hline $\begin{array}{l}\text { Juros sobre capital } \\
\text { próprio }\end{array}$ & $\mathrm{JCP}$ & $\begin{array}{c}\text { Adaptado de Nakao } \\
(2012)\end{array}$ & $\begin{array}{l}6.404 / 76 * / \text { CPC } 03 \text { (IAS 7) } \\
\text { CPC 09. CPC } 18 \text { (IAS 28) }\end{array}$ & Art. 389, RIR/1999 \\
\hline Lucros estrangeiros & LESG & $\begin{array}{l}\text { Dummy - }(1) \text { : } \\
\text { rendimentos no } \\
\text { exterior; }(0) \text { : outros } \\
\text { casos. }\end{array}$ & 6.404/76*/CPC 30 (IAS 18) & $\begin{array}{l}\text { Art. 394, RIR/1999; } \\
\quad \text { IN 213/2002 }\end{array}$ \\
\hline Prejuízos Fiscais & $\mathrm{PF}$ & $\begin{array}{c}\text { Martinez e Passamani } \\
\text { (2014) }\end{array}$ & $6.404 / 76 * /$ CPC 32 (IAS 12) & Art. 389, RIR/1999 \\
\hline Var. Receitas de Vendas & VRV & Valores da DRE & 6.404/76*/CPC 30 (IAS 18) & Art. 389, RIR/1999 \\
\hline Variações Cambiais & VCAMB & $\begin{array}{l}\text { Dummy - (1): valores } \\
\text { na DOAR/DFC; }(0) \text { : } \\
\text { Outros casos. }\end{array}$ & $\begin{array}{c}6.404 / 76 * / \text { CPC } 02 \text { (IAS 21). } \\
\text { CPC } 20 \text { (IAS 23). CPC } 30 \\
\text { (IAS 18) }\end{array}$ & $\begin{array}{c}\text { Arts. } 375 \text { e } 377, \\
\text { RIR/1999. MP } \\
2.158 / 2001 \\
\end{array}$ \\
\hline Book-Tax-Differences & BTD & $L A I R_{i}-\frac{D E S P I R_{-} C S L L_{i}}{0,34}$ & \multicolumn{2}{|c|}{ Variável Dependente } \\
\hline
\end{tabular}

*Legislação para antes das IFRS. **Também foram consideradas as aplicações da IN RFB 1.515/2014. DRE: Demonstração do Resultado. BP: Balanço Patrimonial. DOAR: Demonstração de Origens e Aplicações. DFC: Demonstração do Fluxo de Caixa. IN: Instrução Normativa. RIR: Regulamento do Imposto de Renda. LAIR: Lucros antes dos Impostos. DESPIR_CSLL: Despesas de imposto de renda e contribuição social sobre o lucro líquido. 0,34: Alíquota máxima dos impostos sobre o lucro no Brasil. MP: Medida provisória.

Ainda há de se destacar que itens como impostos de fronteiras, planos de aposentadorias e ações como formas de remuneração não foram aplicados no modelo devido às especificações legislacionais dos países que foram estudados nas pesquisas anteriores. Além disso, características e condições de negócios das empresas - porte, estrutura de capital, liquidez das ações, rentabilidade, auditoria, estrutura de propriedade, por exemplo - não foram aplicadas por não representarem as diferenças Book-Tax decorrentes das normas. Outras variáveis, de estimativas com perdas de créditos de clientes, provisões, ágio de expectativa futura e as considerações do CPC 12, CPC 06 e do CPC 46, que poderiam explicar as diferenças normativas no Brasil, não foram utilizadas no modelo devido a ocorrência incipiente nas operações das empresas. Sobre os créditos de liquidação duvidosa, a sua não consideração pode ser explicada, além da não significância, pelas diferentes formas de reconhecimentos consideradas no contexto brasileiro, sendo: antes das IFRS: perdas estimadas, de 2008 a 2012: perdas incorridas, e de 2013 até hoje: perdas estimadas. Essas variações podem prejudicar as generalizações do modelo e a interpretação dele.

\subsection{As BTD Anormais e a Persistência dos Resultados Contábeis e Tributários}

Para a associação das BTD Anormais mensuradas em (1) e a persistência dos resultados contábeis foi adaptado o modelo de Sloan (1996), que considera a capacidade preditiva dos accruals e dos fluxos de caixa operacionais nos resultados líquidos futuros das empresas. Para atender aos interesses de análise, inseriu-se no modelo de Sloan (1996) a variável BTDAN e suas interações BTDAN*ACCRUALS e BTDAN*FCO. Para a persistência dos resultados tributários os procedimentos são similares (Equações 2 e 3). 


$$
\begin{aligned}
& L_{i, t+1}=\beta_{1} \text { Accruals }_{i, t}+\beta_{2} \text { FCO }_{i, t}+\beta_{3} \text { BTDAN }_{i, t}+\beta_{4} \text { Accruals }_{i, t} * \text { BTDAN }_{i, t} \\
& +\beta_{5} F_{C O} O_{i, t} * B T D A N_{i, t}+\beta_{6} T A M_{i, t}+\beta_{7} R O A_{i, t}+\beta_{8} L E V_{i, t}+\beta_{9} G T W_{i, t} \\
& +\beta_{10} A U D_{i, t}+\alpha_{i}+\varepsilon_{i, t} \\
& L T_{i, t+1}=\beta_{1} \text { Accruals }_{i, t}+\beta_{2} \text { FCO }_{i, t}+\beta_{3} \text { BTDAN }_{i, t}+\beta_{4} \text { Accruals }_{i, t} * \text { BTDAN }_{i, t} \\
& +\beta_{5} F_{C O} O_{i, t} * B T D A N_{i, t}+\beta_{6} T A M_{i, t}+\beta_{7} R O A_{i, t}+\beta_{8} L E V_{i, t}+\beta_{9} G T W_{i, t} \\
& +\beta_{10} A U D_{i, t}+\alpha_{i}+\varepsilon_{i, t}
\end{aligned}
$$

Em que, $L L_{i, t+1}$ : São os resultados líquidos das empresas em $t+1 ; L T_{i, t+1}$ : São os resultados tributários das empresas em $\mathrm{t}+1$, mensurados segundo Hanlon (2005); Accruals $i_{i, t}$ : São os accruals totais calculados em t, conforme Jones (1991); $F C O_{i, t}$ : Fluxos de Caixa operacionais em t; BTDAN $N_{i, t}$ : São as $B T D$ Anormais estimadas para empresas i em t; Accruals $_{i, t} * B T D A N_{i, t}$ : São as interações dos accruals e as BTD Anormais; $F C O_{i, t} * B T D A N_{i, t}$ São as interações dos fluxos de caixa operacionais e as BTD Anormais; Controles: TAM - logaritmo do ativo total da empresa; ROA - lucro líquido sobre os ativos totais; LEV - exigível total sobre os ativos totais; GTW - variável para crescimento, variação das receitas de vendas em t e t-1 divididos por t-1, e AUD - variável dummy (1): empresas auditadas pelas BIG Four; (0): outras. As outras variáveis já foram descritas anteriormente.

Sobre a consideração dos accruals e as BTD Anormais na mesma modelagem, discorre-se que outros estudos, como de Martinez e Passamani (2014), Formigoni et al. (2009), e Piqueiras (2010), encontraram relações pequenas ou até não significativas entre estas duas variáveis. No entanto, a explicação principal para a utilização de ambas está na lógica de que os accruals só captam o gerenciamento de resultados contábeis, enquanto as BTD Anormais também possuem informações sobre o gerenciamento de tributos, o que amplia as avaliações desta pesquisa. Caminho semelhante foi considerado por Costa, Nakao e Moraes (2017), que consideraram as BTD e a suavização dos resultados no mesmo modelo.

Espera-se que, para as duas equações, os coeficientes $\beta_{3}, \beta_{4}$ e $\beta_{5}$ sejam negativos e significativos, indicando a queda das persistências dos resultados contábeis e os tributários com as influências das BTD Anormais. Para $\beta_{1}$ e $\beta_{2}$, nas equações (2) e (3), não há uma definição de sinal, mas espera-se que os valores de $\beta_{1}$ sejam menores do que $\beta_{2}$. Os testes foram realizados nos períodos de 2002 a 2015; 2010 a 2015 e 2002 a 2007 (além disso, operacionalizou-se um modelo com uma dummy para full IFRS, sendo (1): de 2010 a 2015, e (0): outros anos, com exceção a 2008 e 2009). Após as IFRS, espera-se que os coeficientes $\left(\beta_{3}, \beta_{4}\right.$ e $\left.\beta_{5}\right)$ sejam menores do que no período anterior à adoção (ou seja, valores mais negativos). As variáveis, quando necessário, foram divididas pelo ativo total em t, nas equações (2) e (3), mais especificamente as seguintes variáveis: Accruals, FCO e BTDAN.

\subsection{Considerações Analíticas}

Para a operacionalização deste estudo foi utilizado o software Eviews 7® e aplicou-se a técnica de dados em painel dinâmico com o método de momentos generalizados (GMM). A escolha dessa técnica se deve aos problemas de heterocedasticidade, autocorrelação e endogeneidade dos dados analisados, que inviabilizaram a aplicação do painel estático com mínimos quadrados ordinários $(O L S)$, mínimos quadrados generalizados $(G L S)$ ou semidiferença. Sobre a endogeneidade, observouse que o painel dinâmico pode limitar os seus problemas, principalmente a simultaneidade de variáveis, situação verificada nos modelos de $B T D$, e a inserção das variáveis dependentes defasadas nos modelos (que foram adicionadas nas equações (1), (2) e (3) quando das operacionalizações dos resultados). A adição de defasagens em dados em painel estático acarretaria problemas nas modelagens.

Na aplicação dos dados em painel dinâmico, nas equações (1), (2) e (3), esta pesquisa utilizouse dos instrumentos em primeiras diferenças e buscou inserir as variáveis que fossem mais exógenas 
aos modelos. Os valores do J-statistic, do p-value/Sargan e as autocorrelações indicaram as adequabilidades das operacionalizações.

\section{RESULTADOS E DISCUSSÕES}

Inicialmente, é importante apresentar alguns resultados. No modelo de apuração das BTD Anormais verificou-se que todas as variáveis foram significativas e com os sinais esperados. $\mathrm{O}$ erro da regressão, que representa as BTD Anormais, indicou médias mais negativas de 38.963,79 (ponderada pelo ativo total, seu escore é -0,096539), sendo que após a adoção das IFRS, as BTD Anormais são superiores em comparação ao período de 2002 a 2007.

$\mathrm{Na}$ amostra, de 2002 a 2015, notou-se que as empresas possuem: altas variabilidades em seus resultados contábeis e tributários, accruals com médias negativas e fluxos de caixa operacionais positivos, portes similares, rentabilidades negativas, endividamentos significativos e demonstrações auditadas em grande parte por firmas BIG Four (Tabela 1). Além disso, ressalta-se que as correlações observadas não indicaram multicolinearidade nos dados.

Tabela 1 - Estatísticas descritivas das variáveis dos modelos, (2) e (3), período de 2002 a 2015

\begin{tabular}{cccccccc}
\hline Variáveis & Média & Mediana & Máximo & Mínimo & $\begin{array}{c}\text { Desvio } \\
\text { Padrão }\end{array}$ & $\begin{array}{c}\text { VIF* } \\
\text { Modelo } \\
\text { LL }\end{array}$ & $\begin{array}{c}\text { VIF* } \\
\text { Modelo } \\
\text { LT }\end{array}$ \\
\hline LL & 128282,80 & 20984,00 & 6388740,00 & $-8325767,00$ & 528468,00 & - & - \\
LT & 191466,50 & 36676,47 & 5332762,00 & $-2800612,00$ & 483601,40 & - & - \\
BTDAN & $-38963,79$ & $-7318,615$ & 4190506,00 & $-5575184,00$ & 608737,10 & 1,0155 & 1,0155 \\
ACCRUALS & $-101258,90$ & -12048 & 7834710,00 & $-7857842,00$ & 584923,60 & 1,2262 & 1,2232 \\
FCO & 442251,30 & 79902,50 & 10359620,00 & $-1761129,00$ & 953403,10 & 2,0889 & 2,0785 \\
TAM & 13,72909 & 13,88407 & 18,06713 & $1,098612,00$ & 2,075412 & 2,2056 & 2,1935 \\
ROA & $-0,03386$ & 0,031228 & 111,3333 & $-56,53608,00$ & 2,426041 & 1,8284 & 1,7502 \\
LEV & 117,0904 & 60,20000 & 12985,90 & 0,100000 & 511,0644 & 1,8353 & 1,7495 \\
GTW & 0,444274 & 0,109660 & 301,5543 & $-3,055065$ & 6,489485 & 1,2021 & 1,2001 \\
AUD & 0,573210 & 1 & 1 & 0 & 0,494677 & 1,3135 & 1,2968 \\
\hline
\end{tabular}

*Variance Inflation Factor.

\subsection{Resultados do Modelo BTD Anormais e Persistência dos Resultados Contábeis}

Discorre-se sobre os achados encontrados para as relações entre as BTD Anormais e a persistência dos resultados contábeis. Inicialmente, é significativo ressaltar que para esse modelo, período completo e após as IFRS, esta pesquisa aplicou dados em painel dinâmico com o método GMM. Na análise inicial com dados em painel estático, os modelos apresentaram estimações inconsistentes e problemas que restringiam os pressupostos necessários para as regressões. Assim, com o GMM, com instrumentos em primeiras diferenças, ocorreram operacionalizações mais robustas. Os resultados para o período de 2002 a 2015 e após as IFRS são apresentados na Tabela 2.

$\mathrm{Na}$ Tabela 2 verificou-se que o modelo é robusto quanto ao GMM, J-statistic de 96,270 e $p$ value superior a $5 \%$ e $10 \%$. Além disso, foi adequada a escolha dos instrumentos devido a amostra maior do que a quantidade de instrumentos aplicados no modelo. Os resultados ainda evidenciaram a ausência de autocorrelação de segunda ordem com a não rejeição da hipótese nula, ausência de autocorrelação dos resíduos. Com base nisso, com os resultados pode-se rejeitar a hipótese $1_{\text {a }}$ de que, para o período de 2002 a 2015, as BTD Anormais diminuem a qualidade dos lucros (persistência). 
Tabela 2 - Resultados do modelo das BTD Anormais e a Persistência dos Resultados Contábeis, de 2002 a 2015 , e somente após as IFRS

$$
\begin{array}{cc} 
& L L_{i, t+1}=L L_{i, t}+\beta_{1} A_{c c r u a l s}+\beta_{2, t} F C O_{i, t}+\beta_{3} B T D A N_{i, t}+\beta_{4} \text { Accruals }_{i, t} * B_{T D A N}+ \\
\text { Equação } & \beta_{5} F C O_{i, t} * B T D A N_{i, t}+\beta_{6} T A M_{i, t}+\beta_{7} R O A_{i, t}+\beta_{8} L E V_{i, t}+\beta_{9} G T W_{i, t}+\beta_{10} A U D_{i, t}+\alpha_{i}+\varepsilon_{i, t}
\end{array}
$$

\begin{tabular}{|c|c|c|c|c|c|}
\hline \multirow{2}{*}{ Variáveis } & \multirow{2}{*}{ Sinais Preditos } & \multicolumn{2}{|c|}{ Período Completo } & \multicolumn{2}{|c|}{ Após as IFRS } \\
\hline & & Coeficientes & $\mathbf{t}$ & Coeficientes & $\mathbf{t}$ \\
\hline LL\# & + & $-0,495548$ & $-9,595829 *$ & $-0,668630$ & $-7,136609 *$ \\
\hline ACCRUALS & + & 0,059751 & $1,837787 * * *$ & 0,220228 & $6,336928 *$ \\
\hline $\mathrm{FCO}$ & + & 0,598064 & $9,595217^{*}$ & 0,489192 & $7,722874 *$ \\
\hline BTDAN & - & 0,000619 & 0,464214 & $-0,000276$ & $-0,158601$ \\
\hline ACCRUALS*BTDAN & - & $-0,042094$ & $-2,969955^{*}$ & $-0,213350$ & $-2,490010 * *$ \\
\hline FCO $*$ BTDAN & - & 0,061938 & $6,372887^{*}$ & 0,044907 & $6,747687^{*}$ \\
\hline TAM & $+/-$ & $-0,030122$ & $-4,584719 *$ & $-0,172249$ & $-10,12531 *$ \\
\hline ROA & + & 0,352176 & $6,751242 *$ & 0,479736 & $5,656316^{*}$ \\
\hline LEV & - & $-0,000797$ & $-3,029982 *$ & $-0,001351$ & $-5,449320 *$ \\
\hline GTW & - & $-0,053914$ & $-3,439401 *$ & $-0,033647$ & $-1,354945$ \\
\hline AUD & + & $-0,128929$ & $-4,661213 *$ & 0,110122 & $1,960241 * *$ \\
\hline Número de Observações & & \multicolumn{2}{|c|}{1293} & \multicolumn{2}{|c|}{742} \\
\hline J-statistic & & \multicolumn{2}{|c|}{84,656} & \multicolumn{2}{|c|}{53,099} \\
\hline Rank de Instrumentos & & \multicolumn{2}{|c|}{68} & \multicolumn{2}{|c|}{47} \\
\hline
\end{tabular}

Significância das variáveis: *(à 1\%); **(à 5\%) e ***(à 10\%). Em Instrumentos em primeiras diferenças a Constante é suprimida. Instrumentos - período completo: @DYN(LL(+1),-2); ACCRUALS; BTDAN; FCO*BTDAN; TAM; LEV e GTW; Instrumentos - Após as IFRS: @DYN(LL(+1),-2); BTDAN; ACCRUALS*BTDAN; FCO*BTDAN. \#Variável inserida no GMM.

Diante disso, por meio dos resultados, discutem-se as relações apresentadas no modelo. Notou-se que os resultados líquidos anteriores não são persistentes para os resultados líquidos futuros, encontrou-se associações negativas e significativas. As variáveis ACCRUALS e FCO apresentaramse significativas, ambas com sinais positivos. Como esperado, o fluxo de caixa operacional é mais persistente em nove vezes do que os accruals, conforme é evidenciado por Sloan (1996) e esperado para esta pesquisa.

Em relação as implicações das BTD Anormais, observou-se que esses componentes das $B T D$ por si não se mostraram com associações significativas. As suas interações com os ACCRUALS e o FCO apresentaram-se com associações negativas e positivas com a variável dependente, respectivamente.

Com os resultados, mostrou-se que as BTD Anormais, mesmo que não em todas as variáveis analisadas, podem diminuir a persistência dos resultados contábeis por meio dos accruals. Este achado evidencia que, como Hanlon (2005) indicou, as BTD são uma "red flag" para a persistência dos resultados. Para Jackson (2015); Blaylock, Shevlin e Wilson (2012), e Martani, Fitriasari e Yulianti (2010), as BTD são prejudiciais para a persistência, pois podem ser representações de práticas para o gerenciamento de resultados e o planejamento tributário agressivo. No Brasil, Martinez e Bassetti (2016) mostraram que as BTD não são significativas para explicar os ciclos de vida das empresas e a persistência dos resultados. No entanto, Martinez, Souza e Monte-Mor (2016), em seus estudos, encontraram associações negativas entre as BTD e a persistência dos resultados.

Os resultados para a interação FCO*BTDAN foram contrários ao esperado. Isso pode ser explicado pela presença de componentes extremos e até transitórios nos reconhecimentos discricionários das BTD Anormais. Por exemplo, a empresa pode utilizar as diferenças temporárias, nos tributos diferidos, para atrasar ou adiantar os impostos a serem recolhidos. Estas variações de reconhecimentos têm implicações nos fluxos de caixa das entidades, o que pode prejudicar a persistência desses componentes contábeis na presença das BTD Anormais (Ebrahimi \& Saeedi, 2010). Em suma, os fluxos de caixa podem estar sendo reconhecidos incorretamente nas performances futuras das empresas. 
Ainda foi analisado se existem diferenciações quanto as relações das BTD Anormais na persistência dos resultados contábeis devido aos sinais desses componentes discricionários das $B T D$, no período de 2002 a 2015 (valores não tabulados). Visualizou-se que as BTD Anormais positivas diminuem a persistência dos accruals em mais $29,74 \%$ em comparação às $B T D$ Anormais negativas (orientação aumento dos resultados). Já as BTD Anormais negativas amenizam a valoração futura do fluxo de caixa operacional em aproximadamente mais $90 \%$ do que as BTD Anormais positivas (orientação de diminuição dos resultados, pagamento de menos tributos). Estes achados também são constatados em Martinez, Souza e Monte-Mor (2016), que mostraram valores mais altos das BTD totais, sem a separação em componentes discricionários, influenciando negativamente antes e após as IFRS a persistência dos resultados. Já Martani, Fitriasari e Yulianti (2010), na Indonésia, indicaram que as $B T D$ negativas têm impactos mais representativos na persistência do que pequenas $B T D$.

Quanto às variáveis de controle, observou-se que empresas menores, mais rentáveis, mais endividadas e com baixa variação das receitas de vendas apresentaram mais persistência dos resultados contábeis, conforme o esperado. Somente a variável auditoria pelas BIG Four apresentou relação contrária à esperada, não favorecendo a qualidade dos resultados contábeis.

Além da análise da amostra em seu período completo, esta pesquisa discorreu sobre as relações das BTD Anormais após a adoção das IFRS $\left(\mathrm{H}_{2 \mathrm{a}}\right)$. Os resultados estão apresentados na Tabela 2 .

Para o período após a adoção das IFRS, também realizado e adequado com o modelo estimado em GMM, os resultados apontaram direcionamentos similares a amostra com o período total, ou seja, as variáveis ACCRUALS e FCO apresentaram os mesmos sinais e significâncias para a persistência dos resultados contábeis.

Em relação as associações das BTD Anormais, verificou-se que essa parcela discricionária das BTD diminuiu a persistências dos accruals para os resultados líquidos, com sinal negativo e significativo (a relação for maior em quatro vezes em comparação aos achados do período completo). Martinez, Souza e Monte-Mor (2016) encontraram resultados semelhantes no Brasil para as BTD sem a separação em Normais e Anormais. Para a interação FCO*BTDAN a relação foi contrária a esperada. Isso talvez possa ser explicado, conforme Carvalho (2015), pelo reconhecimento incorreto dos gerenciamentos de resultados após as IFRS nos lucros das empresas. Com estes padrões, a subjetividade aumentou e a discricionariedade tornou-se mais possível. Além disso, com as IFRS, as estimativas econômicas são mais presentes, com apurações a valores justo e presente, por exemplo, diminuindo a valoração correta e relevante dos fluxos de caixa para os resultados presentes e futuros das entidades. Nas variáveis de controle, com exceção das variações das receitas de vendas, todas as outras foram significativas com os sinais esperados. A operacionalização com a dummy Full IFRS apresentou os mesmos resultados obtidos anteriormente (não tabulados).

Ainda, para complementação, operacionalizou-se o modelo para o período anterior à adoção das IFRS (não tabulado), o modelo também se mostrou robusto para o GMM, e nos achados desta pesquisa as relações entre as variáveis foram distintas. Os resultados demonstraram que os lucros líquidos diminuem a persistência e o fluxo de caixa operacional é positivo e significativo para aumentar a persistência dos resultados contábeis.

Para as associações das BTD Anormais, notou-se que os sinais negativos preditos foram alcançados e as variáveis foram significativas. Tanto os componentes discricionários das $B T D$, como as suas interações com os ACCRUALS e o FCO diminuíram a capacidade preditiva dos resultados contábeis. A variável ROA foi a única de controle significativa, com o sinal esperado. Quanto maior a rentabilidade, maiores as perspectivas de persistências de resultados líquidos para as empresas.

Com esses resultados é possível discutir a hipótese 2 a. Com a adoção das IFRS no Brasil, ocorreram incentivos para a separação progressiva entre as Contabilidades Financeira e a Tributária (Costa, 2012; Nakao, 2012), gerando possibilidades para maiores BTD (Morais, Sauerbronn \& Macedo, 2015). No entanto, são recorrentes as discussões sobre a implementação das IFRS no país e as práticas realizadas pelas empresas. Para este estudo, partiu-se da premissa de que com maiores 
$B T D$, maiores são os incentivos para a discricionariedade das $B T D$. Logo, a pesquisa esperava efeitos mais representativos das BTD Anormais no período de 2010 a 2015.

Com isso, notou-se que $\mathrm{H}_{2 \mathrm{a}}$ é rejeitada, pois as influências das BTD Anormais foram mais destacadas somente na sua interação com os ACCRUALS para a diminuição da persistência dos resultados contábeis. No período da adoção das IFRS, nessa interação, indicou-se uma diminuição da persistência de 67,96\% superior ao período anterior às IFRS, ou seja, as BTD Anormais diminuíram, em mais de seis vezes, a capacidade dos accruals explicarem os lucros futuros das empresas, quando considerado o período de adoção dos padrões contábeis internacionais no Brasil.

\subsection{Resultados do Modelo BTD Anormais e Persistência dos Resultados Tributários}

Adicionalmente à análise das relações das BTD Anormais na persistência dos resultados contábeis, este estudo investigou as associações desse tipo de BTD sobre os resultados tributários. Esta pesquisa considerou os apontamentos de Lev e Nissim (2004), que consideram os lucros tributários como ferramentas informativas para as empresas. Na Tabela 3 apresentam-se os resultados para o período completo e após as IFRS da amostra.

Tabela 3 - Resultados na apuração do modelo das BTD Anormais e a Persistência dos Resultados Tributários, de 2002 a 2015, e somente após as IFRS

\begin{tabular}{|c|c|c|c|c|c|}
\hline \multirow{3}{*}{ Variáveis } & \multicolumn{5}{|c|}{ 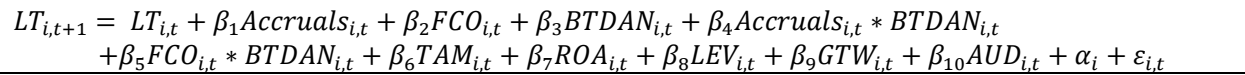 } \\
\hline & \multirow{2}{*}{ Sinais Preditos } & \multicolumn{2}{|c|}{ Período Completo } & \multicolumn{2}{|c|}{ Após as IFRS } \\
\hline & & Coeficientes & $\mathbf{t}$ & Coeficientes & $\mathbf{t}$ \\
\hline LT\# & + & 0,247229 & $13,765^{*}$ & 0,032608 & $2,302091 *$ \\
\hline ACCRUALS & + & 0,392971 & $10,99409 *$ & $-0,031825$ & $-3,221824 *$ \\
\hline $\mathrm{FCO}$ & + & $-0,58489$ & $-16,01087^{*}$ & 0,024222 & 0,990284 \\
\hline BTDAN & - & $-0,065328$ & $-7,686846^{*}$ & $-0,004415$ & $-4,947564^{*}$ \\
\hline ACCRUALS*BTDAN & - & $-0,79173$ & $-13,82639 *$ & $-0,021196$ & $-3,112676^{*}$ \\
\hline FCO $*$ BTDAN & - & $-0,220183$ & $-8,719698 *$ & 0,018122 & $4,880433^{*}$ \\
\hline TAM & $+/-$ & $-0,047308$ & $-8,00192 *$ & $-0,039113$ & $-6,660282 *$ \\
\hline ROA & + & 0,213739 & $6,516755^{*}$ & 0,078968 & $6,556064 *$ \\
\hline LEV & - & $-0,000403$ & $-2,535314 * *$ & 0,000640 & $5,533353 *$ \\
\hline GTW & - & $-0,077584$ & $-10,36832 *$ & $-0,049446$ & $-1,852499 * * *$ \\
\hline AUD & + & 0,137382 & $3,724788^{*}$ & 0,023287 & 0,967153 \\
\hline Número de Observações & & \multicolumn{2}{|c|}{1269} & \multicolumn{2}{|c|}{730} \\
\hline J-statistic & & \multicolumn{2}{|c|}{57,851} & \multicolumn{2}{|c|}{57,200} \\
\hline Rank de Instrumentos & & \multicolumn{2}{|c|}{71} & \multicolumn{2}{|c|}{52} \\
\hline
\end{tabular}

Significância das variáveis: *(à 1\%); **(à 5\%) e ***(à 10\%). Em Instrumentos em primeiras diferenças a Constante é suprimida. Instrumentos - período completo: @DYN(LT(+1),-2); BTDAN; ACCRUALS*BTDAN; FCO*BTDAN; ROA e LEV; Instrumentos - Após as IFRS: @DYN(LT(+1),-2); ACCRUALS; FCO; BTDAN; FCO*BTDAN; TAM; ROA, e LEV. \#Variável inserida no GMM.

Para o período completo, o modelo também foi operacionalizado com dados em painel dinâmico com GMM. Essa aplicabilidade é justificada pelos mesmos motivos que contemplaram os modelos das BTD Anormais e a persistência dos resultados contábeis. Com isso, notou-se achados robustos para o GMM, com J-statistic de 57,851 e seu p-value de 0,17089, e os instrumentos incluídos foram considerados válidos, amostra maior do que 71 instrumentos. Não se indicou a presença de autocorrelação de segunda ordem.

Os achados mostraram que o LT e os accruals presentes são positivos e significativos para a persistência dos lucros tributários futuros. Em contrapartida, os fluxos de caixa operacionais são relacionados negativamente com a variável dependente. Estes achados podem demonstrar que os accruals podem estar se revertendo, em média, mais rapidamente como fluxo de caixa, indicando a sua persistência.

Em relação as associações das BTD Anormais, observou-se que esses componentes por si só e as suas interações com os accruals e os fluxos de caixa operacionais são negativas e significativas, 
conforme o esperado, diminuindo a persistência dos resultados tributários. Estas constatações não rejeitam a hipótese $1_{\mathrm{b}}$.

Estes resultados são indícios de que as BTD Anormais também representam possibilidades de gerenciar os tributos. As relações negativas sobre a persistência mostram tentativas de alterar os resultados tributários nas empresas. Kajimoto e Nakao (2018) salientam esses achados ao mostrarem que a baixa persistência dos lucros tributários no Brasil é uma forma de planejamento tributário para a evasão fiscal. Os interesses dos gestores com a utilização das discricionariedades das BTD levam a interpretações das normas tributárias que lhes proponham benefícios.

Os sinais das BTD Anormais contribuem para os achados desta pesquisa. Os resultados não tabulados indicaram que as BTD Anormais positivas amenizam em mais de $113 \%$ a persistência dos resultados tributários em comparação às $B T D$ Anormais negativas. Para o fluxo de caixa operacional, os efeitos das BTD Anormais negativas são mais destacados, com a diminuição da persistência dos lucros tributários em três vezes mais em comparação às BTD Anormais positivas. Essa percepção salienta o gerenciamento de tributos (Desai \& Dharmapala, 2009) que os gestores buscam para diminuir o pagamento de impostos pelas empresas.

Nas variáveis de controle, os resultados encontrados demonstraram que empresas menores, com alta rentabilidade, maior endividamento, baixa variabilidade das receitas e auditadas pelas $B I G$ Four têm os resultados tributários mais persistentes. Os achados foram conforme o esperado.

Esta pesquisa também separou a amostra para os períodos posteriores à adoção das IFRS, sendo os resultados evidenciados na Tabela 3. No período posterior à adoção das IFRS, o modelo aplicado com dados em painel com GMM é robusto e mostrou-se adequado para a sua interpretação. Com isso, primeiramente, observou-se que as variáveis LT e ACCRUALS presente foram significativas. No entanto, FCO não foi significativa.

Para as variáveis que representam as BTD Anormais, notou-se que esses componentes das BTD diminuem a persistência por si só e dos accruals, conforme o esperado. O que mostra a diminuição da capacidade valorativa de informações contábeis nos lucros tributários devido à discricionariedade dos gestores - assimetria informacional. Para as BTD Anormais e o fluxo de caixa, os resultados foram contrários. Uma possível explicação vem das constatações de Kajimoto e Nakao (2018), que o fluxo de caixa é significativamente importante na composição do lucro tributário, mas estes tipos de informações são para apurar os tributos e não tomar decisões. Além disso, com as IFRS, como ocorreram poucas alterações na legislação tributária, esperava-se que a persistência continuasse, mas o regime tributário de transição pode ter provocado incerteza e causado o reconhecimento incorreto do fluxo de caixa, junto com o gerenciamento de resultados, valorando positivamente a persistência nas empresas.

Em termos de magnitudes de coeficientes, os valores das IFRS não foram superiores em comparação ao período completo. Ainda se destaca que, com a dummy Full IFRS, os resultados encontrados são semelhantes aos anteriores.

Nas variáveis de controle, empresas maiores, com baixa rentabilidade e com altas variações nas receitas de vendas possuem menor persistência dos resultados tributários (conforme o esperado). Em contrapartida, as variáveis LEV e AUD não apresentaram as relações esperadas.

Como complemento, nos resultados do período de 2002 a 2007, considerando também o modelo adequado para o GMM, evidenciou-se novamente que o fluxo de caixa operacional é mais persistente para os lucros tributários do que os accruals. Além disso, em meios gerais, percebeu-se que as BTD Anormais possuem influências menos representativas do que no período após a adoção das IFRS. Somente a interação ACCRUALS*BTDAN apresentou a associação negativa e esperada, mas com coeficiente menor.

Nas variáveis de controle, somente LEV mostrou-se significativa e com o sinal esperado. Os resultados indicaram que empresas mais endividadas possuem menor persistência dos resultados tributários. Isso pode indicar que os gestores podem manipular os resultados devido aos riscos contratuais ou o favorecimento na renegociação desses contratos de dívidas, diminuindo a 
consistência dos lucros tributários. Além disso, os benefícios adquiridos com o endividamento podem amenizar os montantes dos lucros tributários.

Com todos esses achados é possível discutir a hipótese $\mathrm{H}_{2 \mathrm{~b}}$. A indicação é a de aceitação parcial dessa hipótese, pois se observou efeitos mais significativos das BTD Anormais na persistência dos resultados tributários após a adoção das IFRS somente as BTDAN e ACCRUALS*BTDAN. Essa constatação pode ser explicada pelo aumento das $B T D$ nesse período, pela queda da informatividade do lucro tributário (Kajimoto \& Nakao, 2018) e, ainda, os indicativos da literatura em considerar as $B T D$ como ferramentas para o planejamento tributário, sem preocupações informacionais (Martinez \& Dalfior, 2015; Machado \& Nakao, 2012; Hanlon, 2005). Além disso, pode-se argumentar que a conformidade mandatória das normas contábeis e fiscais no período de 2002 a 2007 pode ter restringido as práticas discricionárias das $B T D$ Anormais em diminuir a qualidade dos resultados contábeis, conforme a vertente da literatura defendida por alguns autores (Tang \& Firth, 2011; Lev \& Nissim, 2004).

Sobre as BTD Anormais e suas implicações no contexto após as IFRS, é ainda importante discutir que os resultados encontrados mistos podem ser explicados pelas percepções de Kraft (2015) e Bouaziz e Omri (2011), que argumentaram sobre a situação de mercados de capitais menos desenvolvidos, com o reconhecimento de informações inadequado, como as BTD como reflexos de atividades de gerenciamento de resultados e o fluxo de caixa, conjuntamente, aumentando a persistência dos resultados contábeis e tributários. Neste caso, as BTD discricionárias podem induzir decisões equivocadas sobre as performances das entidades. Para Carvalho (2015), os acionistas possuem deficiências para identificar e reconhecer os accruals anormais, como as BTD Anormais, nos resultados das empresas.

Por outro lado, foi possível perceber, principalmente na persistência dos resultados tributários, que as BTDAN e sua interação com os accruals já são indícios de diminuição na qualidade dos lucros. Os valores mais altos das $B T D$, mais evidentes nas IFRS, podem traduzir os números contábeis em previsões mais otimistas e tendenciosas em relação aos resultados das empresas, causando assimetria de informações e prejuízos para os investidores. Assim, nesta pesquisa se comprovou ainda mais que as $B T D$ podem ser consequências de práticas de gerenciamentos.

Por fim, como teste complementar, notou-se que os resultados são similares quando as $B T D$ Anormais são apuradas com os reflexos das normas contábeis e das leis tributárias não imediatamente nas empresas, ou seja, assumiu-se a defasagem em t-1 das variáveis independentes da equação (1).

\section{CONSIDERAÇÕES FINAIS}

Com a premissa teórica da Teoria de Agência, nos conflitos de interesses entre os agentes e o principal, e a pressuposição da assimetria informacional - ou seja, como as BTD Anormais são reflexos de atividades para o gerenciamento de resultados, isso pode causar incentivos para modificações nas informações, que podem não ser repassadas aos investidores, diminuindo a qualidade dos lucros reportados - este estudo objetivou avaliar as relações das $B T D$, como reflexos de atividades para o gerenciamento de resultados, na persistência dos resultados contábeis e tributários em empresas de capital aberto listadas no Brasil. O interesse principal desta pesquisa foi confirmar se as BTD Anormais podem diminuir as capacidades informacionais dos dados contábeis e tributários, contemplando exclusivamente suas propriedades preditivas e valorativas.

Com os resultados, inicialmente, percebeu-se que a medida proposta para a apuração das BTD Anormais no Brasil é adequada e evidencia as práticas de manipulações. A estimação desse componente discricionário das BTD mostrou sua natureza heterogênea entre as empresas e nos períodos analisados. Além disso, seu comportamento médio foi mais negativo $(-38.963,79)$ e a presente pesquisa identificou variações nos anos anteriores e posteriores à adoção das IFRS. Ainda, notou-se que essa proxy apresentou correlações positivas com os accruals discricionários e negativas com variáveis de compliance tributária. 
Com estas percepções, o presente analisou as relações dessa medida das BTD Anormais na persistência dos resultados contábeis e tributários. Para a persistência dos resultados contábeis, no período de 2002 a 2015, indicou-se a rejeição de $\mathrm{H}_{1 \mathrm{a}}$. Os resultados indicaram que as BTD Anormais por si só não demonstram associação significativa, e somente a sua interação com os accruals diminuíram as suas capacidades preditivas para os resultados líquidos futuros de empresas do mercado de ações nacional. As associações negativas e significativas mostraram que esses componentes discricionários das $B T D$ representam práticas oportunistas dos gestores, que causam assimetria informacional de dados passados para projeções futuras. Para a interação com o fluxo de caixa, a relação contrária pode ser explicada pelos componentes transitórios das BTD Anormais.

Nos resultados para os períodos anteriores e posteriores à adoção das IFRS, as percepções foram similares. Com a rejeição de $\mathrm{H}_{2 \mathrm{a}}$, a presente pesquisa indicou que as implicações das BTD Anormais, nos accruals, são mais pronunciados em amenizar a persistência dos resultados contábeis após a adoção das IFRS. O aumento das BTD nesse período e a maior discricionariedade permitida aos gestores com esses padrões são explicações para os achados encontrados.

Os resultados da análise das afetações das BTD Anormais na persistência dos resultados tributários apontaram para a não rejeição da hipótese $\mathrm{H}_{1 \mathrm{~b}}$. As $B T D$ Anormais diminuíram as capacidades dos accruals e do fluxo de caixa operacional em preverem os lucros tributários das empresas analisadas. As tendências para o gerenciamento de tributos e a utilização das normas fiscais com os interesses pessoais dos gestores podem explicar essas associações. Para a hipótese $\mathrm{H}_{2 \mathrm{~b}}$, os achados indicaram para a sua aceitação parcial. A conformidade mandatória financeira-fiscal inibiu os impactos mais representativos das BTD Anormais no período de 2002 a 2007, diferentemente dos anos de 2010 a 2015.

Diante do exposto, esta pesquisa apresentou contribuições para essa área de estudo. As evidências encontradas indicaram que as BTD no Brasil capturam distorções induzidas pelas motivações dos gestores em gerenciar os resultados contábeis e os tributários, mas isso é mais evidente nos accruals e na persistência dos resultados tributários. Essas percepções se diferenciam dos incentivos que influenciam as BTD decorrentes das normas regulatórias. A motivação dos gestores por recompensas pessoais indica que há a utilização da discricionariedade dos padrões contábeis e das lacunas permitidas pela complexidade da legislação fiscal para criar incertezas na qualidade dos lucros reportados das empresas situadas no Brasil. Esse fato só prejudica a credibilidade dos dados nos reportes contábeis e fiscais e ainda diminui a eficiência dessas informações como relevantes para o mercado de capitais brasileiro.

Além do exposto, esta pesquisa ainda apresentou outras contribuições, sendo: i) mostrou-se que a utilização das BTD Anormais no Brasil indicou para as consideráveis práticas de gerenciamento de resultados e evasão fiscal no país, o que prejudica a qualidade dos lucros nas empresas; ii) as evidências indicaram para influências das BTD Anormais após a adoção das IFRS. Essas constatações vão de encontro às discussões da efetiva implementação das IFRS no Brasil. Os motivos na literatura para a ineficácia das IFRS no país - falta de infraestrutura contábil e das empresas, despreparo dos profissionais, má preparação educacional, altos custos de conformidade e desinteresse - são vários, para sustentar os achados deste estudo; iii) teoricamente, o estudo também confirmou as discussões da Teoria de Agência. Houve a constatação de que os conflitos de interesses geram a assimetria informacional por meio das BTD Anormais, e iv) os resultados desta pesquisa ainda têm implicações para os recorrentes debates sobre a conformidade financeira-fiscal nos países.

Apesar dos resultados, esta pesquisa possui limitações. Primeiramente, a base de dados oferecida no país, que possui algumas limitações. No entanto, para sanar esse problema, houve a conciliação em diversas bases de informações. Além disso, houve a utilização de somente um modelo para a persistência, outros existem, mas a escolha desta pesquisa não invalida os achados encontrados.

Por fim, o estudo indica algumas sugestões futuras. Recomenda-se a realização de pesquisas com as BTD Anormais em comparação com outros países. Recomenda-se também a investigação dos fatores característicos das empresas e ambientais que influenciam na formação das BTD Anormais. 
Além disso, sugere-se ainda uma abordagem mais qualitativa para entender as BTD Normais e Anormais sob os vieses comportamentais dos gestores e das empresas, adicionando novos conhecimentos para área.

\section{REFERÊNCIAS}

Ahmed, K., Chalmers, K., \& Khlif, H. (2013). A meta-analysis of IFRS adoption effects. The International Journal of Accounting, 48(2), 173-217.

Blaylock, B., Shevlin, T., \& Wilson, R. J. (2011). Tax avoidance, large positive temporary book-tax differences, and earnings persistence. The Accounting Review, 87(1), 91-120.

Blaylock, B., Gaertner, F., \& Shevlin, T. (2015). The association between book-tax conformity and earnings management. Review of Accounting Studies, 20(1), 141-172.

Ines, B., \& Ali, O. M. (2011). Market perception of the information content in book-tax differences:

Empirical evidence in Tunisia. Journal of Business Studies Quarterly, 3(1), 112.

Bradshaw, M. T., \& Miller, G. S. (2008). Will harmonizing accounting standards really harmonize accounting? Evidence from non-US firms adopting US GAAP. Journal of Accounting, Auditing \& Finance, 23(2), 233-264.

Brown, J., Lin, K. C., Moore, J. A., \& Wellman, L. (2014). Tax policy uncertainty and the perceived riskiness of tax savings. Arizona State University, Oregon State University, and University of Illinois at Chicago working paper.

Cardoso, T. A. O., Costa, P. S. \& Ávila, L. A. C. (2016) A Persistência da Book-Tax Differences nas Companhias Abertas Brasileiras. In Anais, $X$ Congresso ANPCONT, Ribeirão Preto, SP. ANPCONT.

Carvalho, V. G. (2015). Influência das Informações Tributárias na Previsão dos Analistas Financeiros do Mercado de Capitais Brasileiro (Tese de Doutorado). Universidade de Brasília/Universidade Federal da Paraíba/Universidade Federal do Rio Grande do Norte, Brasília/João Pessoa/Natal.

Chi, S. S., Pincus, M., \& Teoh, S. H. (2013). Mispricing of book-tax differences and the trading behavior of short sellers and insiders. The Accounting Review, 89(2), 511-543.

Comprix, J., Graham, R. C., \& Moore, J. A. (2011). Empirical evidence on the impact of book-tax differences on divergence of opinion among investors. Journal of the American Taxation Association, 33(1), 51-78.

Costa, P. S. (2012). Implicações da adoção das IFRS sobre a Conformidade Financeira e Fiscal das Companhias Abertas Brasileiras (Tese de Doutorado). Universidade de São Paulo, Programa de PósGraduação em Controladoria e Contabilidade, São Paulo.

Costa, P. S.; Nakao, S. H.; Moraes, M. B. C. (2017) Persistence of Book-Tax Differences when firms smooth book and taxable income. In Anais, American Accounting Association Annual Meeting, 2017, San Diego. USA: AAA.

Dechow, P., Ge, W., \& Schrand, C. (2010). Understanding earnings quality: A review of the proxies, their determinants and their consequences. Journal of Accounting and Economics, 50(2-3), 344-401.

Desai, M. A., \& Dharmapala, D. (2009). Corporate tax avoidance and firm value. The Review of Economics and Statistics, 91(3), 537-546.

Dhaliwal, D. S.; Lee, H. S. G.; Pincus, M. (2009) Book-Tax Differences, Uncertainty about Information Quality, and Cost of Capital. University of Arizona, Working Paper.

Dridi, W., \& Adel, B. (2016). Book-Tax Differences and the Persistence of Earnings and Accruals: Tunisian Evidence. Asian Social Science, 12(6), 193-202.

Ebrahimi, M., \& Saeedi, A. (2010). The role of accruals and cash flows in explaining stock returns: evidence from Iranian companies. International Review of Business Research Papers, 6(2), 164-179.

Fields, T. D., Lys, T. Z., \& Vincent, L. (2001). Empirical research on accounting choice. Journal of Accounting and Economics, 31(1-3), 255-307.

Formigoni, H., Antunes, M. T. P., \& Paulo, E. (2009). Diferença entre o lucro contábil e lucro tributável: uma análise sobre o gerenciamento de resultados contábeis e gerenciamento tributário nas companhias abertas brasileiras. BBR-Brazilian Business Review, 6(1), 44-61.

Formigoni, H., Antunes, M. T. P., Paulo, E., \& Pereira, C. A. (2012). Estudo sobre os incentivos tributários para o gerenciamento de resultados contábeis nas companhias abertas brasileiras. Revista Base

(Administração e Contabilidade) da UNISINOS, 9(1), 41-52. 
Frank, M. M., Lynch, L. J., \& Rego, S. O. (2009). Tax reporting aggressiveness and its relation to aggressive financial reporting. The Accounting Review, 84(2), 467-496.

Furtado, L. L., Souza, J. A. S., \& Sarlo Neto, A. (2016). Gerenciamento de resultados contábeis à luz das diferenças entre o lucro contábil e tributário (book-tax differences): uma análise de dados em painel balanceado. Revista Ambiente Contábil, 8(1), 115-132.

Hanlon, M. (2005). The persistence and pricing of earnings, accruals, and cash flows when firms have large book-tax differences. The Accounting Review, 80(1), 137-166.

Hanlon, M., Maydew, E. L., \& Shevlin, T. (2008). An unintended consequence of book-tax conformity: A loss of earnings informativeness. Journal of Accounting and Economics, 46(2-3), 294-311.

Healy, P. M., \& Wahlen, J. M. (1999). A review of the earnings management literature and its implications for standard setting. Accounting horizons, 13(4), 365-383.

Jackson, M. (2015). Book-tax differences and future earnings changes. The Journal of the American Taxation Association, 37(2), 49-73.

Jeanjean, T., \& Stolowy, H. (2008). Do accounting standards matter? An exploratory analysis of earnings management before and after IFRS adoption. Journal of Accounting and Public Policy, 27(6), 480-494.

Jensen, M. C., \& Meckling, W. H. (1976). Theory of the firm: Managerial behavior, agency costs and ownership structure. Journal of Financial Economics, 3(4), 305-360.

Jones, J. J. (1991). Earnings management during import relief investigations. Journal of Accounting Research, 29(2), 193-228.

Kajimoto, C. G. K., \& Nakao, S. H. (2018). Persistência do Lucro Tributável com a Adoção das IFRS no Brasil. Contabilidade Vista \& Revista, 29(1), 130-149.

Kraft, A. (2015). Management Earnings Forecasts and Book-Tax Differences. International Journal of Economics and Finance, 7(3), 1-23.

Lev, B., \& Nissim, D. (2004). Taxable income, future earnings, and equity values. The Accounting Review, 79(4), 1039-1074.

Liao, Y. H., \& Fu, Q. R. (2015). Research on the Correlation between Book-Tax Difference and Earnings Management. In 2015 International Conference on Education Technology and Economic Management. Atlantis Press.

Lyu, C., Yuen, D. C., Zhang, X., \& Zhang, N. (2014). The Impact of IFRS Adoption on Real Activities Manipulation: Evidence from China. Journal of Applied Management Accounting Research, 12(2).

Machado, M. C., \& Nakao, S. H. (2012). Diferenças entre o lucro tributável e o lucro contábil das empresas brasileiras de capital aberto. Revista Universo Contábil, 8(3), 100-112.

Marques, M. T., Nakao, S. H., \& Costa, P. D. S. (2017). Book-Tax Differences and Capital Structure. RAM. Revista de Administração Mackenzie, 18(6), 177-200.

Martani, D., Fitriasari, D., \& Anwar, Y. (2010). Influence of Book Tax Gap Towards Earnings Persistence and Firm Value for the Period of 1999-2007. In The 3rd Accounting \& The 2nd Doctoral Colloquium. Martinez, A. L., \& Passamani, R. R. (2014). Book-Tax Differences e sua relevância informacional no mercado de capitais no Brasil. Revista de Gestão, Finanças e Contabilidade, 4(2), 20-37. Martinez, A. L., de Souza, T. B. T., \& Monte-Mor, D. S. (2016). Book-Tax Differences, Earnings Persistence and Tax Planning Before and After the Adoption of IFRS in Brazil. Advances in Scientific and Applied Accounting, 9(2), 162-180.

Martinez, A. L., \& Dalfior, M. D. (2016). Agressividade Fiscal entre companhias controladoras e controladas. Revista da Receita Federal: estudos tributários e aduaneiros, 2(1), 344-362.

Martinez, A. L., \& Bassetti, M. (2016). Ciclo de vida das empresas, Book-Tax Differences e a persistência nos lucros. Revista de Educação e Pesquisa em Contabilidade (REPeC), 10(2).

Moraes, M. V. M., Sauerbronn, F. F., \& da Silva Macedo, M. A. (2015). E se as Normas Internacionais fossem adotadas para fins fiscais? Evidências empíricas a partir dos ajustes do regime tributário de transição (RTT). Revista Universo Contábil, 11(4), 107-127.

Nakao, S. H. (2012). A adoção de IFRS e o legado da conformidade contábil-fiscal mandatória (Tese de Livre Docência). Universidade de São Paulo, Departamento de Contabilidade e Atuária, Ribeirão Preto. Noga, T. J., \& Schnader, A. L. (2013). Book-Tax Differences as an indicator of financial distress. Accounting Horizons, 27(3), 469-489.

Piqueiras, T. M. (2010). Relação das Diferenças entre o Lucro Contábil e o Lucro Tributável (Book-Tax Differences) e o Gerenciamento de Resultados no Brasil. (Dissertação de Mestrado). Universidade de São Paulo, Programa de Pós-Graduação em Controladoria e Contabilidade, Ribeirão Preto. 
Pereira, M. J. R. C. (2010). A conformidade Book-Tax e o seu impacto nos lucros, nos fluxos financeiros e na fiscalidade. (Tese de Doutorado). Universidade do Porto, Programa de Pós-Graduação em Ciências Empresariais, Porto - Portugal.

Ryu, H., \& Chae, S. J. (2014). The effect of Book-Tax Conformity on the use of Accruals: Evidence from

Korea. Journal of Applied Business Research, 30(3), 753.

Santos, M. A. C., \& Cavalcante, P. R. N. (2014). O efeito da adoção dos IFRS sobre a relevância informacional do lucro contábil no Brasil. Revista Contabilidade \& Finanças, 25(66), 228-241.

Sloan, R. G. (1996). Do stock prices fully reflect information in accruals and cash flows about future earnings? The Accounting Review, 289-315.

Tang, T. Y. (2006). The Value Relevance of Book-Tax Differences-An Empirical Study in China's Capital Market. Available at SSRN. Disponível em: <http://papers.ssrn.com/sol3/papers> .

Tang, T., \& Firth, M. (2011). Can book-tax differences capture earnings management and tax management? Empirical evidence from China. The International Journal of Accounting, 46(2), 175-204.

Tang, T. Y., \& Firth, M. (2012). Earnings persistence and stock market reactions to the different information in book-tax differences: Evidence from China. The International Journal of Accounting, 47(3), 369-397.

Tang, T. Y. (2015). Does book-tax conformity deter opportunistic book and tax reporting? An international analysis. European Accounting Review, 24(3), 441-469.

Yamashita, H., Nakamura, H., Goto, A., \& Hirai, H. (2007). Are Book-tax Differences Useful in Indicating the Persistence of Earnings, Accruals, and Cash Flows in Japan? Journal Japan Industrial Management Association, 58(3), 200-207. 